\title{
Reducing Fuel Consumption Using Flywheel Battery Technology for Rubber Tyred Gantry Cranes in Container Terminals
}

\author{
Kai Hou Tan, Yap Fook Fah \\ School of Mechanical and Aerospace Engineering, Nanyang Technological University, Singapore \\ Email:kaihou@ntu.edu.sg,mffyap@ntu.edu.sg
}

How to cite this paper: Tan, K.H. and Fah, Y.F. (2017) Reducing Fuel Consumption Using Flywheel Battery Technology for Rubber Tyred Gantry Cranes in Container Terminals. Journal of Power and Energy Engineering, 5, 15-33.

https://doi.org/10.4236/jpee.2017.57002

Received: May 22, 2017

Accepted: July 9, 2017

Published: July 13, 2017

Copyright ( 92017 by authors and Scientific Research Publishing Inc. This work is licensed under the Creative Commons Attribution International License (CC BY 4.0).

http://creativecommons.org/licenses/by/4.0/

\begin{abstract}
Flywheel Energy Storage System (FESS) is used as an energy regeneration system to help with reducing peak power requirements on RTG cranes that are used to load or unload container ships. Nevertheless, with the use of FESS, Port Operator can deploy undersized generator for new RTG as this will further reduce fuel consumption. This paper presents the investigation of the amount of energy and fuel consumption that can be reduced in Rubber Tyred Gantry (RTG) cranes in container terminals by the use of simulation. In addition, Variable Speed Generator is integrated to the simulation-hybridized RTG. Simulation results reveal that the total energy saving exceeded $30 \%$ relatively to conventional RTG. A hardware-in-loop system is introduced for the purpose of validating the simulation results. The hardware components procured include a FESS, a Variable Frequency Drive (VFD) and brake resistors.
\end{abstract}

\section{Keywords}

Flywheel Energy Storage System, Rubber Tyred Gantry, Mechanical Battery, Hardware-in-Loop (HIL) Simulation

\section{Introduction}

Flywheel energy storage represents a potentially efficient and environmentally friendly solution with high power charge and discharge, high round-trip efficiency, high cycle tolerance, long calendar life, no temperature sensitivity, no capacity or efficiency fade, and no hazardous materials [1]. The objective of this project is to develop a hardware-in-the-loop simulator for a hybrid Rubber Tyred Gantry (RTG) crane, and to optimize the design of the hybrid RTG crane in terms of performance in relation to cost.

A flywheel stores energy by way of kinetic motion of the spinning rotor. The 
kinetic energy stored is determined by Equation (1).

$$
E k=1 / 2 I \omega 2,
$$

In Equation (1), $E k$ is kinetic energy, $I$ is moment of inertia and $\omega$ is the angular velocity of the flywheel. The most efficient way to increase the stored energy is to increase the spinning speed of the flywheel. A doubling in speed results in a quadruple rise in the stored energy. The maximum speed limit is dependent on the tensile strength of the rotor material and the mechanical stresses developed due to inertial loads. This means that composite materials with low density and high tensile strength are excellent for storing rotational kinetic energy.

Figure 1 shows the basic layout of a FESS. The flywheel is contained inside a vacuum chamber to eliminate windage losses. It is supported by high precision bearings or non-contacting magnetic bearings to minimize friction losses. FESS uses electrical power to charge up a flywheel battery thus converting electrical energy into kinetic energy (Figure 1). This mechanical energy is stored in a rotating mass or flywheel. FESS will supply electrical power when there is a demand in the power line or DC (Direct Current) bus. The rotating speed of the flywheel will ramp down when supplying energy or discharging to a load.

During a RTG crane lifting operation, the diesel engine provides the energy demanded by the hoist motor. At the lowering stage (hoist down), the container's potential energy is converted by the hoist motor into electrical form. This energy is dissipated as heat in resistor banks because there is no means to store this regenerated energy. This resulted in reduced overall system efficiency and increased fuel consumption (Figure 2).

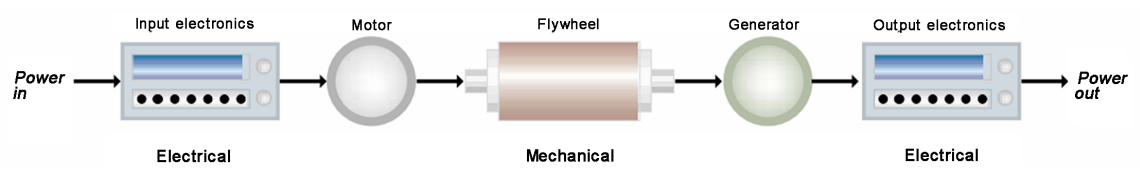

Figure 1. Schematic diagram of energy flow in FESS [2].

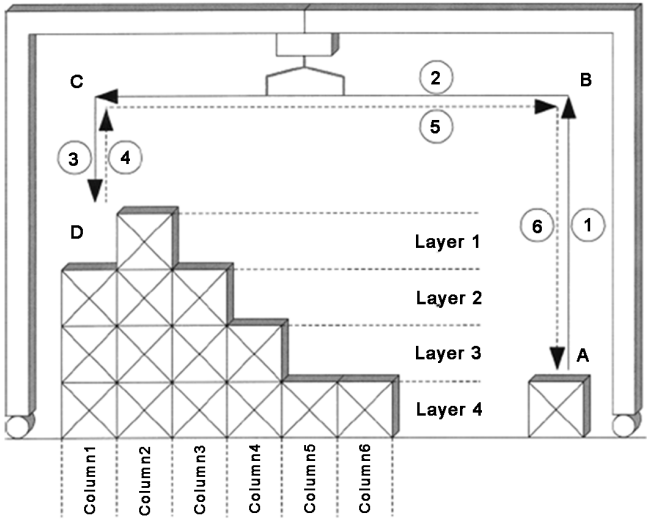

Figure 2. Typical load cycles of RTG [3]. (1): Hoist up, (2): Trolley left, (3): Hoist down, (4): Hoist up, (5): Trolley right, (๑): Hoist down. 
One of the objectives of this project is to determine the effectiveness of Flywheel System in energy saving for RTG crane operations by the use of software simulation. There is no software available in the market that is designed to simulate RTG crane with Flywheel Energy Storage System installed. Therefore a program that is efficient and accurate in simulating different RTG operation scenarios was created for this study (Figure 3 ).

Nevertheless three-dimensional (3D) models and mathematical models of the RTG crane were built. In addition, the first RTG operation scenario was successfully animated using the 3D modeling software-SolidWorks. This paper presents the results achieved in designing and developing a computer model and simulation of a RTG crane hybridized with FESS (Figure 4).

\section{Literature Review and Simulation Data}

In the early stage of this project, the focus was on the understanding of the systems performance of the RTG. Intensive literature review was done to

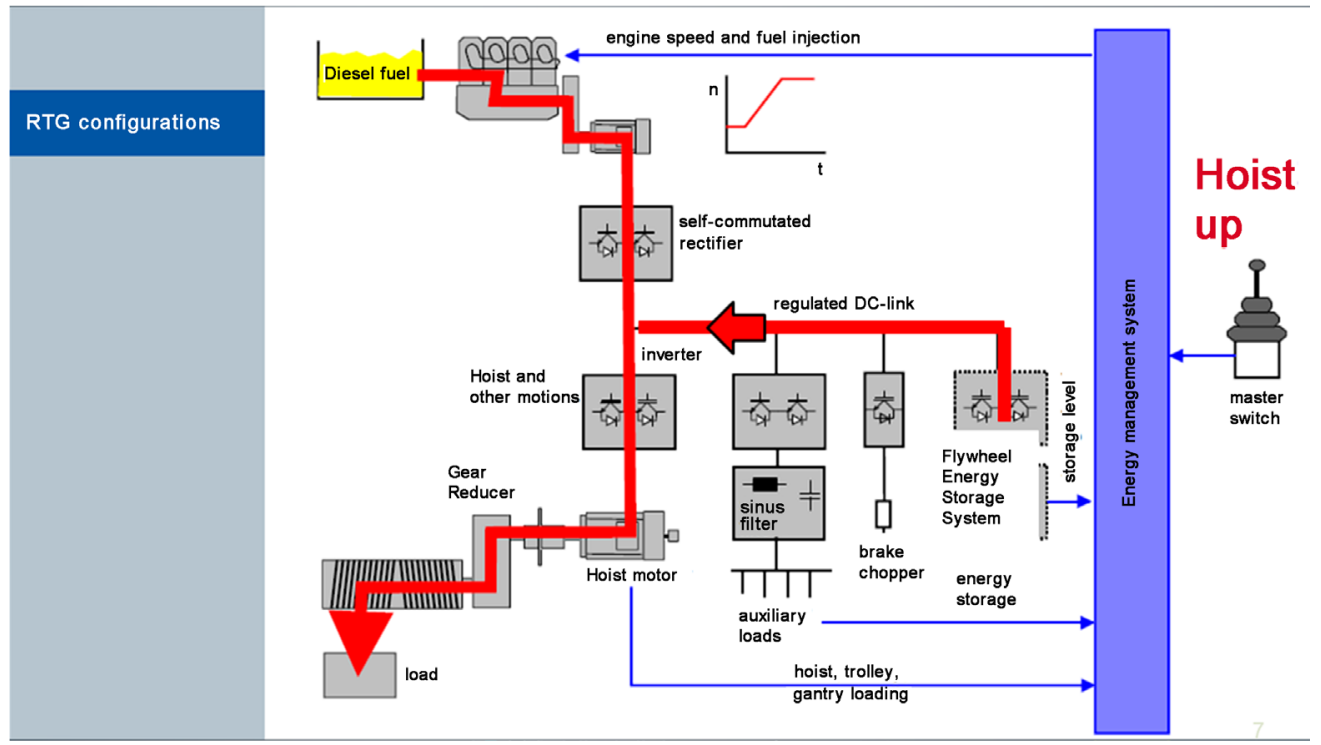

Figure 3. Schematic diagram of energy flow of RTG hybridized with FESS during hoist up [4].

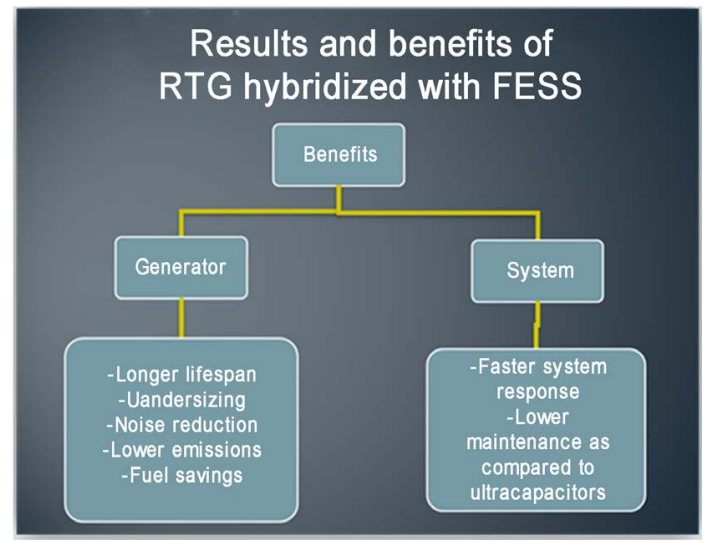

Figure 4. Summary of advantages of using hybridized RTG. 
understand the working principals of the many devices and the components of the RTG. For example the power consumption of the hoist motor, the duration of a hoist cycle, the efficiency of the generator, the power electronics system, etc.

Realistic RTG crane work shifts scenarios must be used in the simulation. Relevant data are collected from research publications and PSA (Port of Singapore) Engineers (Figure 5).

An in-depth review of bearings technology suitable for flywheel system was done because conventional ball bearings cannot be used due to high coasting losses and spin down losses. Active magnetic bearings used in combination with touchdown ball bearings were found to be the most suitable for a flywheel battery (Figure 6).

For minimal energy losses during the flywheel operation, flywheel battery should not be fully discharged before the subsequent charging. The depth of discharge is a function of the efficiency of the flywheel system. The magnitude of this efficiency is found to be dependent on the following factors: type of material used for the rotor, rotating speed of the rotor, type of switching devices used in the power electronics control system and type of bearings used.

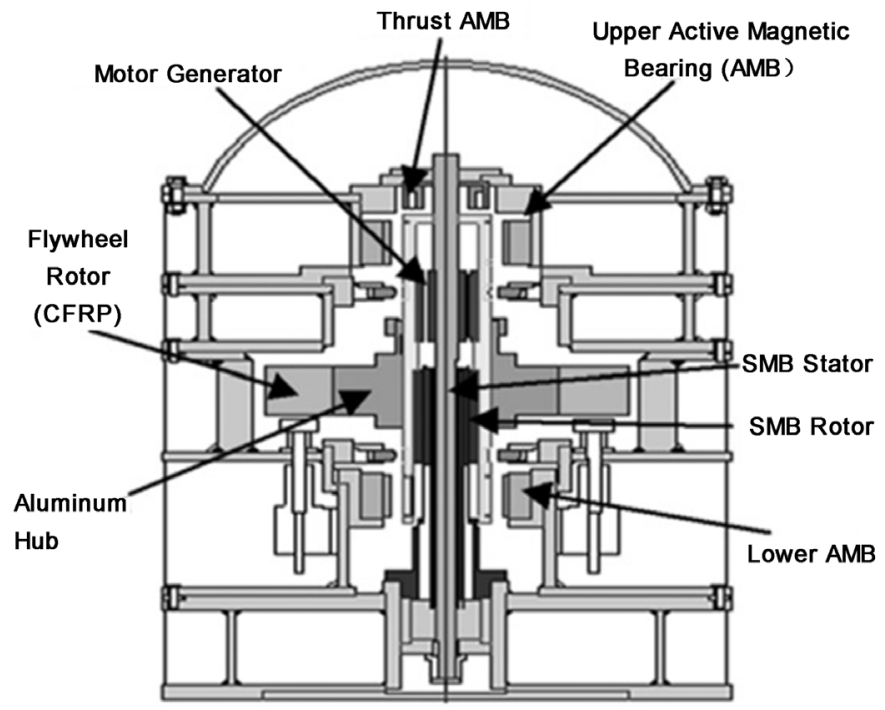

Figure 5. Applications of Active Magnetic Bearing [5].

\section{Advantages of $\mathrm{AMB}$ \\ Non-contact \\ No lubrication required \\ Low maintenance \\ Long life-span \\ Vibration reduction \\ Operate in vacuum}

Figure 6. Pros of using Active Magnetic Bearing [6]. 


\section{Computer Modelling and Simulations}

Using the data and information collected from the literature review, the mathematical modelling is done in the software environment-Matlab. Matlab is a high-level language and interactive environment for numerical computation, visualization, and programming. There are numerous ways to create a simulation program using Matlab. However the speed and stability of the program rely on the programmer's ability to use simple yet effective coding.

The details of the building blocks are not included in this paper. In the final simulation system, multiple lookup tables and logic controls are created to enable user to conveniently build and modify simulation scenarios and parameters.

The simulation results are accurate relative to the information published in research articles. The simulation speed is relatively fast and it is capable of simulating ten RTG operation cycles in less than four minutes. (There is one lifting, one lowering and two trolley regimes in one operation cycle) (Figures 7-9).

\section{Case Studies of Operating Scenarios}

To help in understanding the relationship between the RTG operation scenarios and the energy saved by the FESS, it is essential to create graphical animations of the RTG crane in operation. Therefore the 3D models of the spreader, frame of the crane, operator cabin, spreader, containers and the truck were created using CAD (Computer-Aided Design) software-SolidWorks (Figure 10). Operating scenarios of the RTG are also animated according to the simulations done in the Matlab environment.

A total of nine different simulations of three scenarios are completed and presented in this paper. Three different set of container mass are used for each

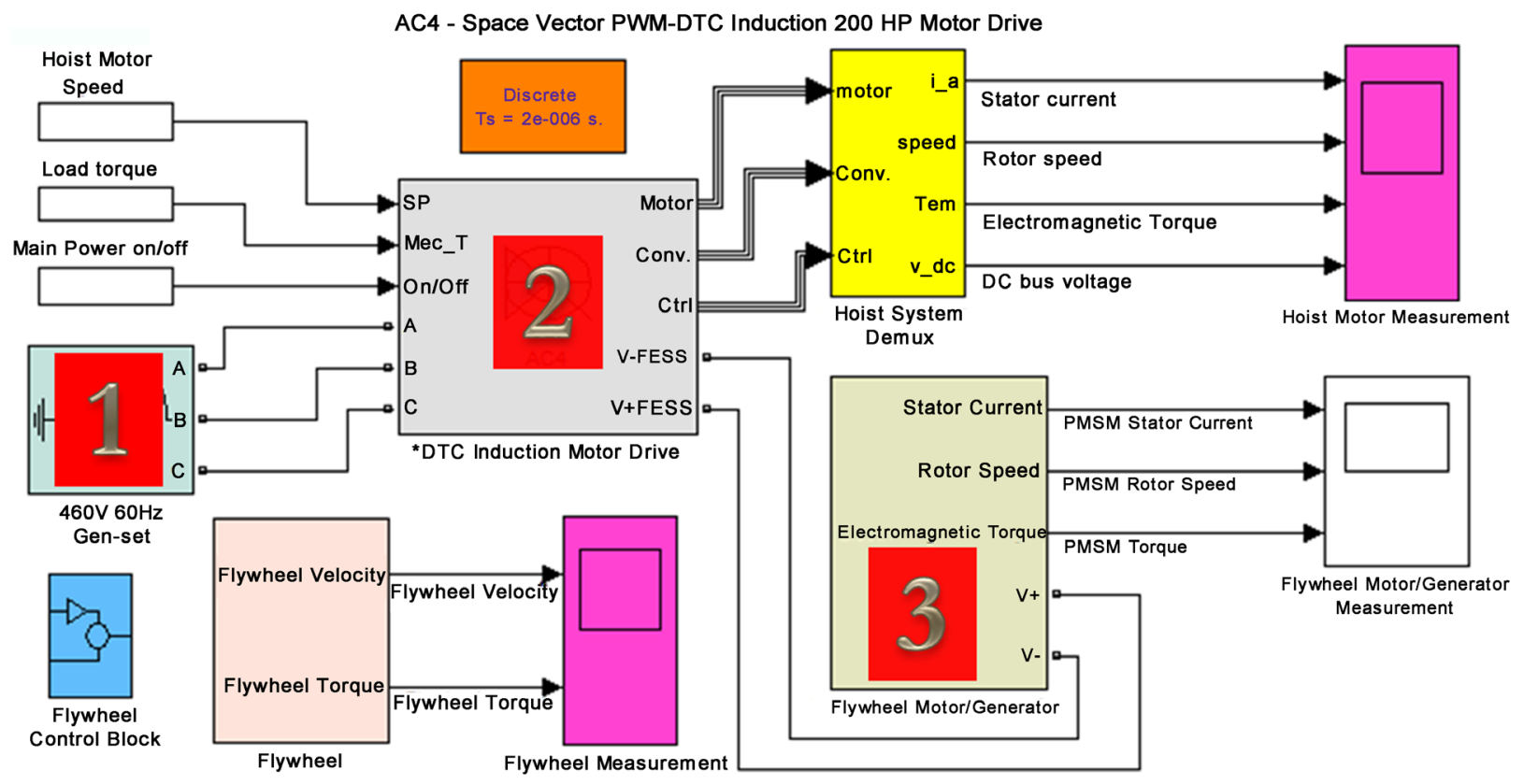

Figure 7. Early version of group of working models integrated to form a hybridized RTG (1. Generator, 2. Hoist motor, 3. Flywheel system). 


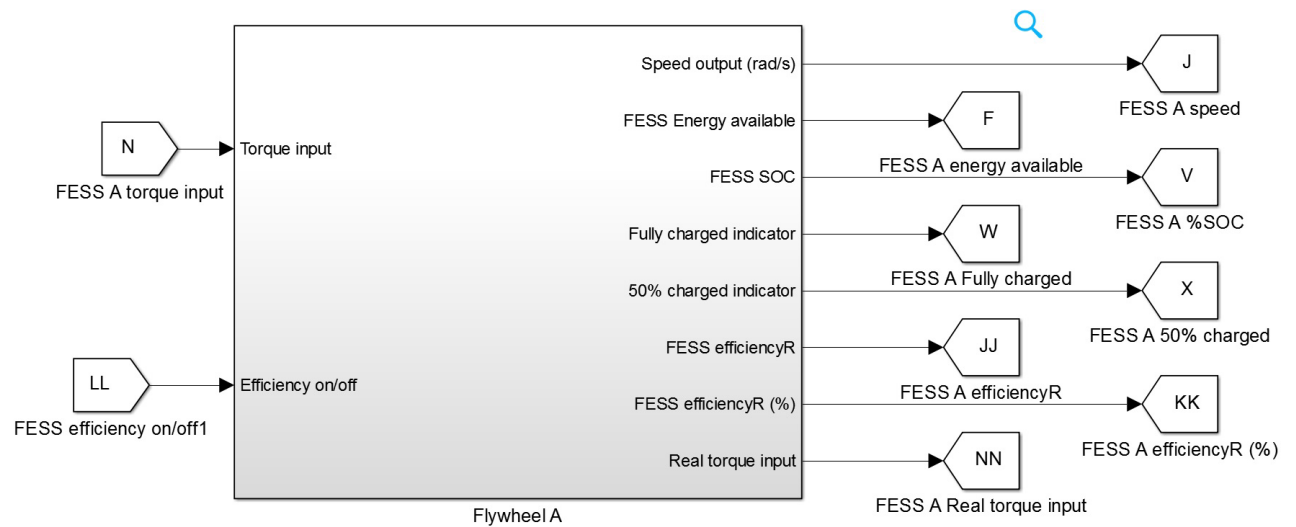

Figure 8. Overview of final building blocks layout of RTG components in Matlabenvironment.
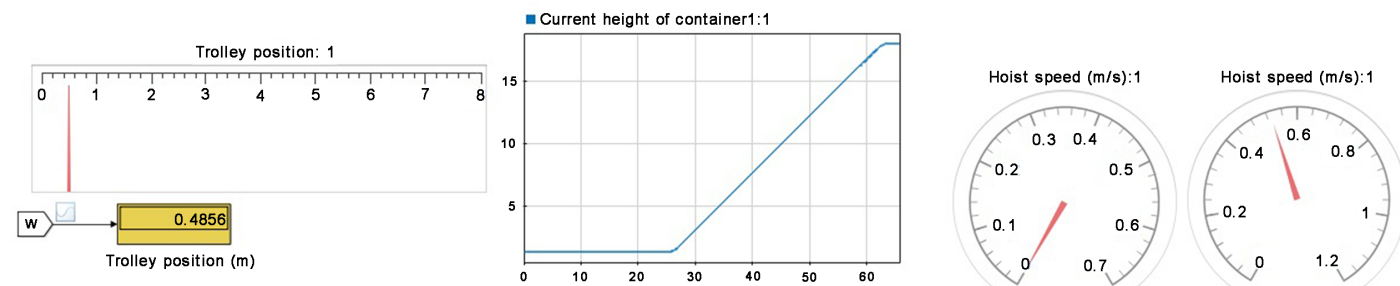

VSG speed (x1000RPM): 1

Braking resistor power dissipation @ hoist down (kW)
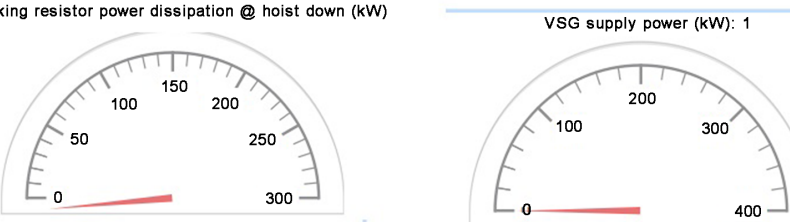

Charging power to FESS from Hoist Down (kW)
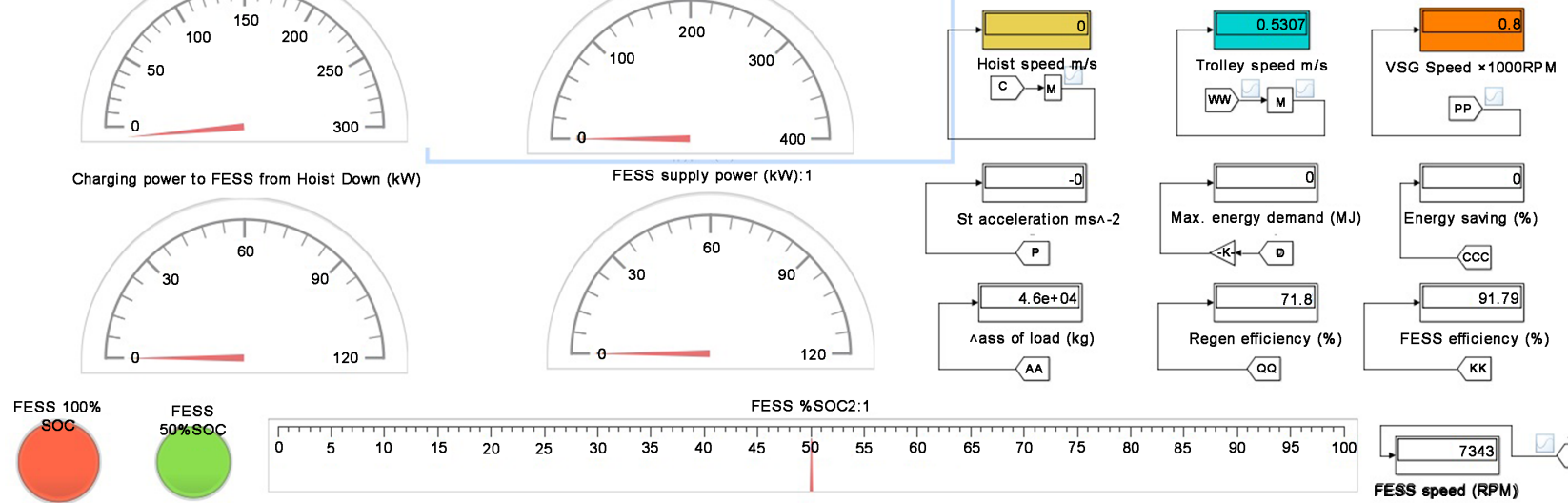

FESS \%SOC2: 1

AA
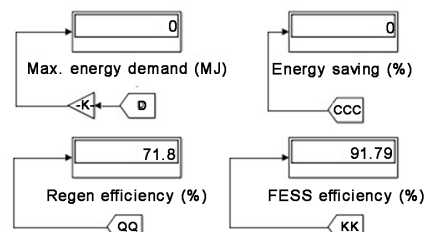

oo

$\mathrm{KK}$

Figure 9. Gauges indicating values of operating parameters of RTG in Matlab.

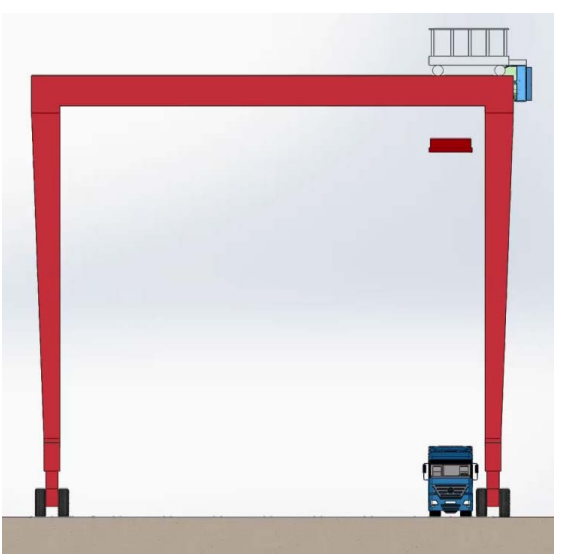

Figure 10. Positions of the spreader and the container before the start of the simulation. 
scenarios and are being categorized into Small Load, Regular Load and Heavy Load. The first operation scenario is presented in Figure 11. The RTG crane hoisted and moved a total of 6 containers from trucks to the positions shown in Figure 11. The sequence of the move follows the numerical number order of the name assigned to the container. For example Container 1 is the first container to be relocated. Scenario One started with the hoist down of the spreader to lift the first container and ended after the spreader is back to the top position after dropping the last container.

To produce accurate results from the simulation, relative to physical RTG crane operations, actual geometrical dimensions of the container are used in calculating the lifting height (Table 1) and the span distance (Table 2) of the spreader [7].

The same FESS parameters, hoisting height table and span distance table are used for all three scenarios.

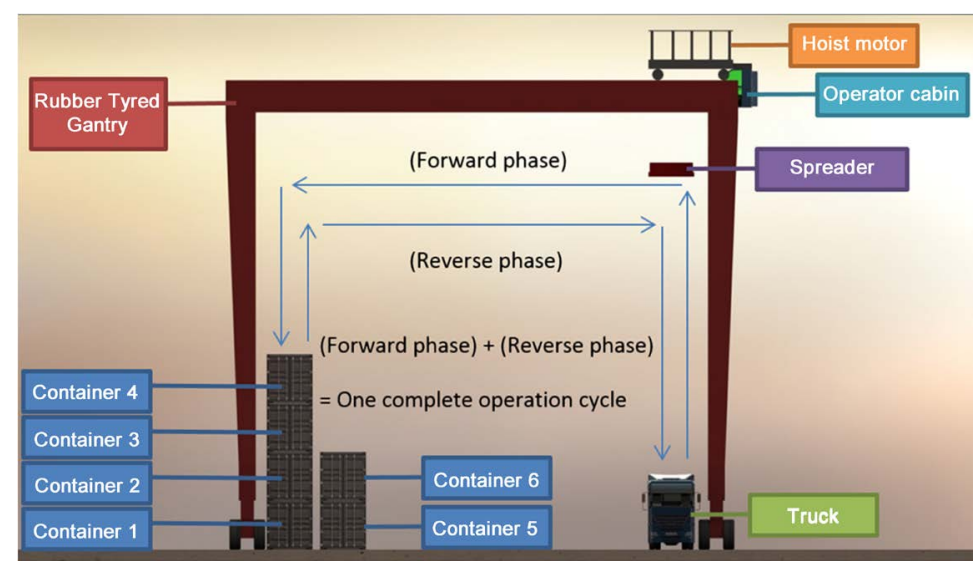

Figure 11. Moving of containers in Scenario One.

Table 1. Lifting height of the RTG.

\begin{tabular}{cc}
\hline Level & Height $(\mathrm{m})$ \\
\hline $\mathbf{1}$ & 2.9 \\
2 & 5.8 \\
$\mathbf{3}$ & 8.7 \\
$\mathbf{4}$ & 11.6 \\
$\mathbf{5}$ & 14.5 \\
$\mathbf{6}$ & 18 \\
\hline
\end{tabular}

Table 2. Span distance of spreader.

\begin{tabular}{cc}
\hline Spreader travel span number & Distance $(\mathbf{m})$ \\
\hline $\mathbf{1}$ & 2.6 \\
$\mathbf{2}$ & 5.2 \\
$\mathbf{3}$ & 7.8 \\
$\mathbf{4}$ & 10.4 \\
$\mathbf{5}$ & 13 \\
$\mathbf{6}$ & 15.6 \\
\hline
\end{tabular}


However before the start of the operation of Scenario Two (Figure 12), there are fixed containers below the span area of the crane. The spreader then proceeds to move containers from trucks to the top of the fixed position containers. Each relocation sequence started from the hoist up of Container 1 and the whole scenario ended with the completion of the hoist up regime of the spreader after dropping Container 10. The whole scenario ended when the spreader was back to the position above the truck.

\subsection{Mass of Containers}

In Scenario One, Two and Three, different loading profiles are used for individual containers (Table 3(a) to Table 3(c)).

The total static loading on the hoist motor is the combination of the weight of the container and the spreader. Three different categories of mass are used for each scenario. Simulation results reveal that greater mass will decrease the amount of energy that can be saved by the FESS.

Hybridizing a RTG does not simply mean the installation of FESS. The control system must be carefully designed to manage the energy flow between the various components of the RTG and the flywheel battery [8]. In this context, the regenerated energy that is stored in the flywheel battery is to be used solely by the hoist motor and not consumed by auxiliary devices or systems. The three working principles used in the simulation energy management system is briefly described in Figure 13. (SOC-State-of-Charge). The same logic control of the energy flow between the flywheel battery and other RTG components is used for all scenarios.

\subsection{Hybridizing the RTG with FESS}

A mechanical flywheel with a rotating mass of $111.6 \mathrm{~kg}$ with moment of inertia of $0.949 \mathrm{kgm}^{\wedge} 2$ is modelled in the simulation. This model has the same specifications as the Vycon VDC-XE FESS that was bought from the company-Vycon

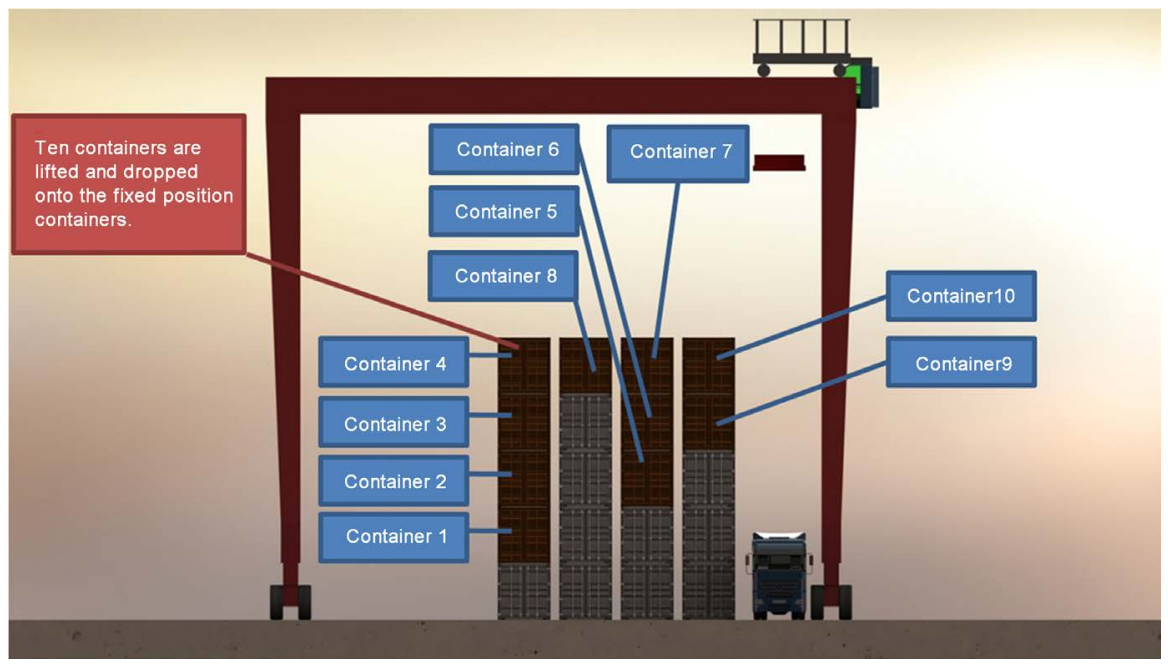

Figure 12. Complete operation cycles of Scenario Two. 
Table 3. (a) Simulation results of Scenario One and mass of containers; (b) simulation results of Scenario Two and mass of containers; (c) simulation results of Scenario Three and mass of containers.

(a)

\begin{tabular}{cccc}
\hline \multicolumn{4}{c}{ Scenario One } \\
\hline Container Number & Small Load (ton) & Regular Load (ton) & Heavy Load (ton) \\
\hline $\mathbf{1}$ & 24 & 30 & 46 \\
$\mathbf{3}$ & 26 & 31 & 45 \\
$\mathbf{4}$ & 28 & 29 & 48 \\
$\mathbf{5}$ & 25 & 38 & 44 \\
$\mathbf{6}$ & 24 & 39 & 42 \\
Average & 24 & 42 & 43 \\
Energy saved using FESS & 25.1 & 34.8 & $\mathbf{3 6 . 7}$ \\
(\% of hoist energy consumed) & $\mathbf{3 9 . 6 \%}$ & $\mathbf{3 7 . 5 \%}$ & \\
Average energy saved in Scenario One (\% of hoist energy consumed): $\mathbf{3 8 \%}$
\end{tabular}

(b)

\begin{tabular}{cccc}
\hline \multicolumn{4}{c}{ Scenario Two } \\
\hline Container Number & Small Load (ton) & Regular Load (ton) & Heavy Load (ton) \\
\hline $\mathbf{1}$ & 24 & 35 & 47 \\
$\mathbf{3}$ & 26 & 40 & 45 \\
$\mathbf{4}$ & 27 & 31 & 47 \\
$\mathbf{5}$ & 25 & 36 & 46 \\
$\mathbf{6}$ & 24 & 33 & 48 \\
$\mathbf{7}$ & 27 & 34 & 44 \\
$\mathbf{8}$ & 25 & 33 & 47 \\
$\mathbf{9}$ & 26 & 38 & 45 \\
$\mathbf{1 0}$ & 24 & 32 & 49 \\
Average & 25 & 39 & 42 \\
Energy saved using FESS & 25.3 & 35.1 & 46 \\
(\% of hoist energy consumed) & $\mathbf{3 1 . 6 \%}$ & $\mathbf{2 9 . 2 \%}$ & $\mathbf{2 8 . 1 \%}$ \\
Average energy saved in Scenario Two (\% of hoist energy consumed): 29.6\%
\end{tabular}

(c)

\begin{tabular}{cccc}
\hline \multicolumn{4}{c}{ Scenario Three } \\
\hline Container Number & Small Load (ton) & Regular Load (ton) & Heavy Load (ton) \\
\hline $\mathbf{1}$ & 24 & 30 & 46 \\
$\mathbf{3}$ & 26 & 31 & 45 \\
$\mathbf{4}$ & 28 & 29 & 48 \\
$\mathbf{5}$ & 25 & 38 & 44 \\
$\mathbf{6}$ & 24 & 39 & 42 \\
Average & 24 & 42 & 43 \\
Energy saved using FESS & 25.1 & 34.8 & 44.7 \\
(\% of hoist energy consumed) & $\mathbf{4 4 . 3 \%}$ & $\mathbf{4 2 . 5 \%}$ & $\mathbf{4 0 . 3 \%}$ \\
Average energy saved in Scenario Three (\% of hoist energy consumed): $\mathbf{4 2 . 4 \%}$
\end{tabular}




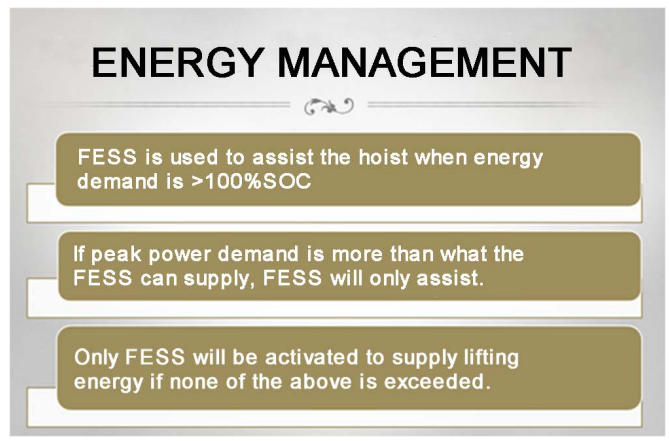

Figure 13. Working principles of energy control system deployed for simulation.

and placed inside NTU (Nanyang Technological University) laboratory. For both the simulation model and the physical FESS, the flywheel system is able to deliver $4000 \mathrm{kWs}$ or $1.11 \mathrm{kWh}$ of energy when the flywheel coast down from $36,750 \mathrm{rpm}$ to $24,500 \mathrm{rpm}$ and discharging energy at a rate of $300 \mathrm{~kW}$.

\subsection{Retrofitting the RTG with VSG}

VSG is a diesel generator that is able to supply optimal amount of energy to match the power demanded by the RTG crane. Moreover it is capable of varying its speed torque performance to reduce energy wastage especially when RTG system demand is low or idling. VSG based algorithms and parameters are used in all simulations but the details are not presented in this paper (Figure 14).

\section{Simulations Results}

Figure 15 is a typical graph that is generated by Matlab after each scenario. The area under this Power-Time graph can be categorized into energy demand, energy supply and energy wastage. It describes the exchange of energy between the hoist motor, FESS and the Variable Speed Generator (VSG). Table 4 is a list of descriptions of the different operation phases in Figure 15.

In addition to the Power-Time graph, the simulation program is able to calculate and display the amount of energy saved after the end of each scenario. Figure 16 gives an overview of the average amount of hoist energy and regenerated energy consumed, and also the total amount of energy saved. The percentage of energy saved is a ratio of regenerated energy to hoist energy.

The total energy saved for a single 300 kilo-Watt (4 mega-joules) flywheel energy storage system, ranges from $29.6 \%$ to $42.4 \%$ of hoisting energy. Numerous factors contribute to the amount of energy saved. These include the containers mass, the hoisting height, flywheel energy storage capacity and the efficiencies of the various components of the hybridized RTG.

Figure 16 reveals that a higher amount of hoist energy demand may not decrease the amount of energy that can be saved by FESS. The two contributing factors of hoist energy are lifting height and the mass of the containers being lifted. Figure 17 and Figure 18 use charts to illustrate the relationship between 


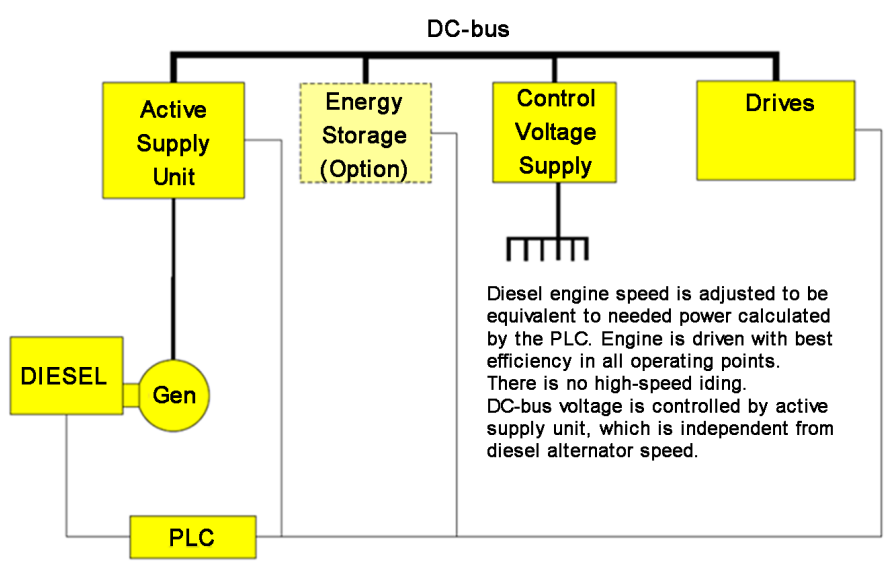

Figure 14. VSG increases RTG energy usage efficiency [5].

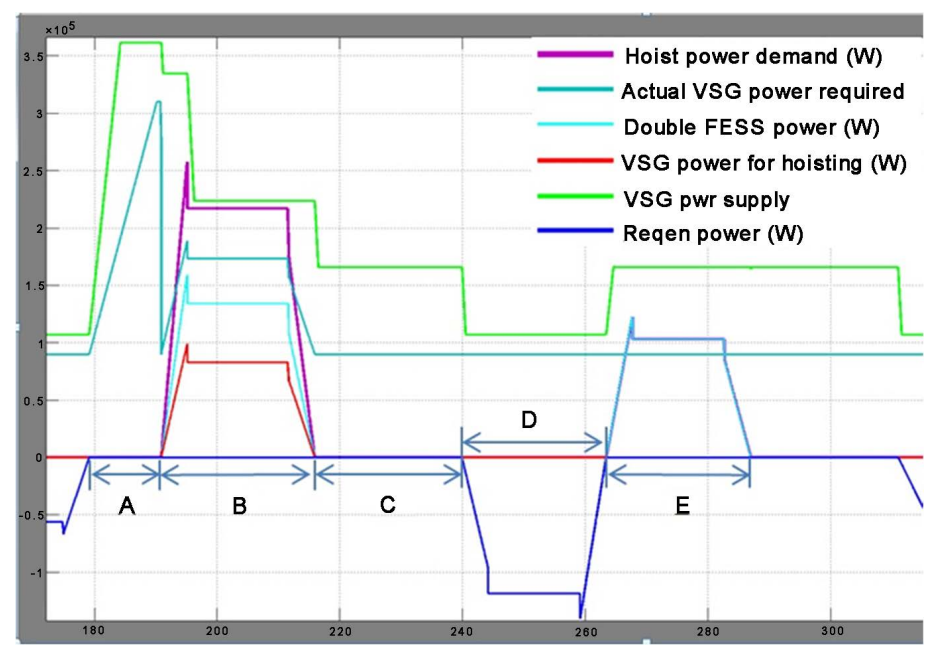

Figure 15. Simulation graphical results (y-axis: power (Watt), $x$-axis: time (seconds)).

Table 4. Descriptions of operation phases.

\begin{tabular}{cl}
\hline Phase & Descriptions of operation \\
\hline A & Variable Speed Generator charges the flywheel to $100 \%$ state-of-charge. \\
B & Hoisting up of container \\
C & Spreader trolley left \\
D & Hoisting down of container. Regenerated energy is used to charge the flywheel. \\
E & $\begin{array}{l}\text { Container is "dropped" and energy from flywheel is used to hoist up the unloaded } \\
\text { spreader. }\end{array}$ \\
\hline
\end{tabular}

the lifting height and energy saving, and relationship between mass of container and energy saving, respectively.

Referring to charts in Figure 17, in Scenario Three, the highest amount of regenerated energy is harvested by FESS and utilized by hoist motor. Conversely, Scenario Two energy saving is the lowest because of greatest lifting height. The 


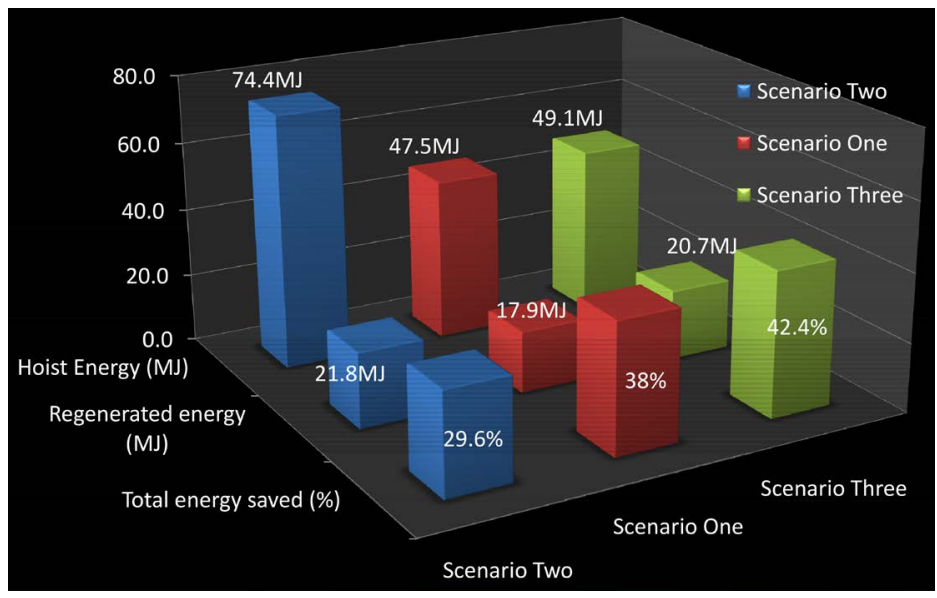

Figure 16. Energy saving in scenarios.

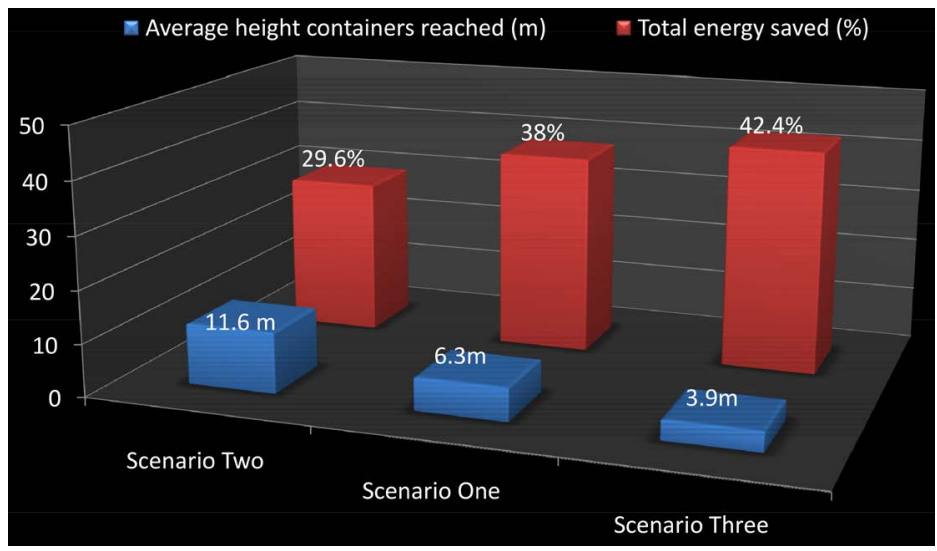

Figure 17. Lifting height and energy saving relationship.

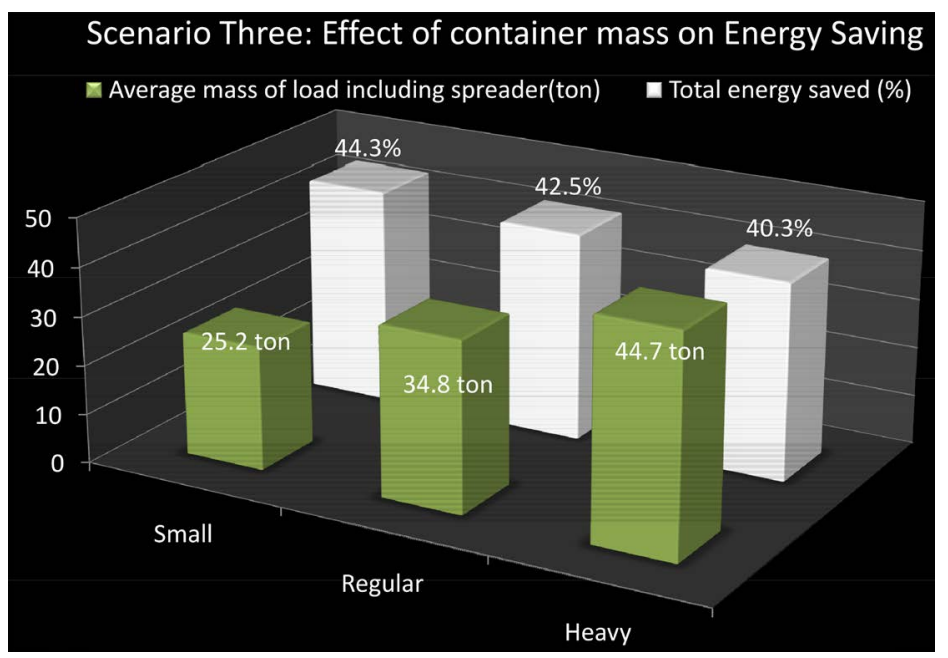

Figure 18. Mass of container and energy saving relationship in Scenario Three.

reason that higher lifting height reduces energy saving is because the hoist down distance is shorter thus resulting in lesser amount of regenerated energy that can be transferred to the flywheel. 
Figure 18 charts use simulation data from Scenario Three and it reveal that an increase in the mass of the container will reduce the percentage of hoist energy that can harvested by the FESS. This is because the energy storage capacity of the flywheel remains constant and is not able to increase with the rise of the amount of regenerated energy. Nevertheless heavier mass increases the regenerated energy when containers are lowered and when flywheel is fully charged, excess energy is dissipated in heat resistors. In short, energy saving is inversely proportional to the mass of the container.

Figure 19 provides the numerical figures of the average amount of energy saved for all the nine simulations. $36.7 \%$ of the hoist energy is being regenerated and reused for hoisting. Numerous simulations have also been done to determine the range of energy saving that can be achieved by FESS. The results always fall within the range of $25 \%$ to $45 \%$ of the total hoist energy consumed.

\section{Simulations Using RTG Fitted with Conventional Diesel Generator and without VSG and FESS}

After a series of typical hoisting simulations were done on a RTG crane, installed with conventional diesel generator, (without Variable Speed Control System), the results are obtained and presented in Figure 20. RTG crane operation

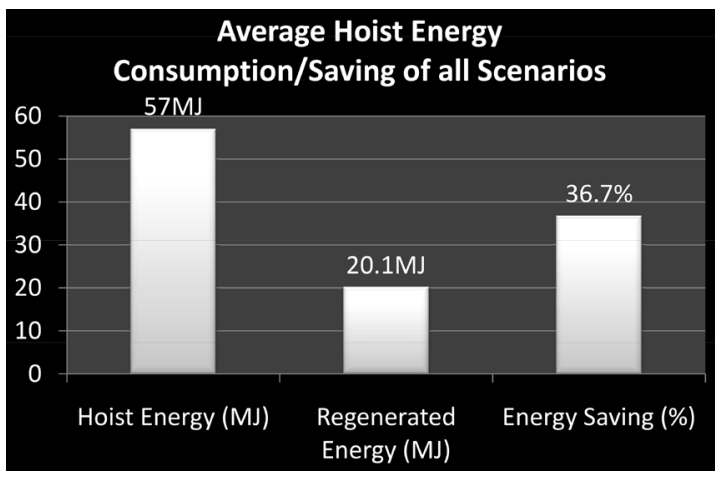

Figure 19. Average hoist energy consumption and saving of all scenarios.

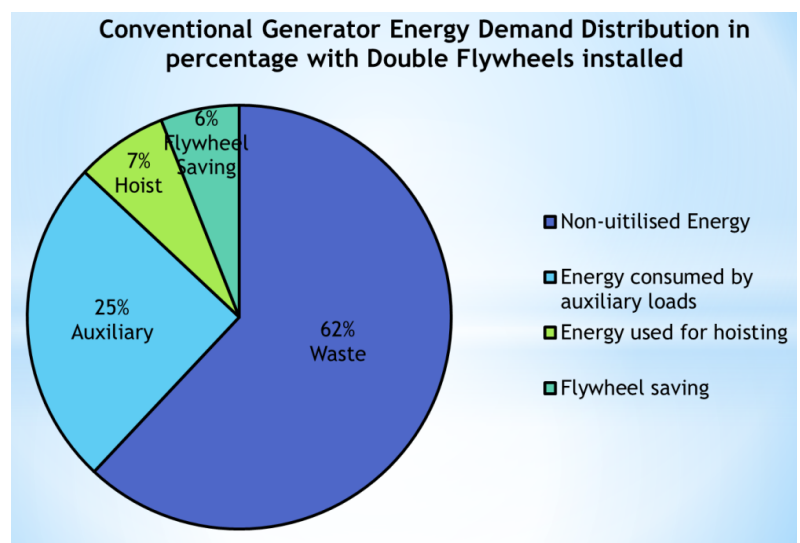

Figure 20. RTG crane energy demand distribution chart when conventional diesel generator is used. 
Scenario One is used for this series of case studies. Simulation results reveal that when a conventional diesel generator is used, a significant amount of energy $(62 \%)$ is wasted and dissipated in the form of heat. This finding is true relative to the diesel generator data provided by PSA (Port of Singapore).

Furthermore, according to PSA, the total power demand of the auxiliary load is approximately $90.8 \mathrm{~kW}$. This converts to $25 \%$ of the total energy produced. After considering this fact, the total amount of energy used for hoisting is only $13 \%$ of the total energy that is provided by the diesel engine. In other words, a maximum amount of $13 \%$ of total energy can be harnessed and stored in the flywheel. Simulation results show that out of this $13 \%$, a double flywheel system is able to utilize $6 \%$ of the energy. It means, simply, that the diesel generator only needs to use $7 \%$ of its energy for doing its main task-hoisting. Flywheel system is indeed effective in reducing energy usage for hoisting.

The conclusion that can be drawn from the above results is that a higher relative amount of energy saving by FESS can be achieved with the adaptation and implementation of a speed load demand optimization system for the diesel generator, or simply a variable speed generator.

\section{RTG Flywheel System Configurations for Laboratory Hardware-in-Loop Simulations}

The components of a RTG can be categorized into energy source, energy sink and energy storage. Figure 21 and Figure 22 show the types of hardware components that are used to model the energy demand/supply systems of a physical RTG crane in laboratory.

To replicate a physical RTG energy flow in laboratory, a Variable Frequency Drive (VFD) can be used to manage the energy flow between the energy source, sink and storage component. A similar setup (Figure 23) was done by Vycon for their flywheel compatibility testing.

Vycon, a Southern California company, has developed their flywheel system to reduce hoist energy consumption in RTG. Vycon has conducted numerous tests and experiments on RTG using their flywheel systems. In addition,
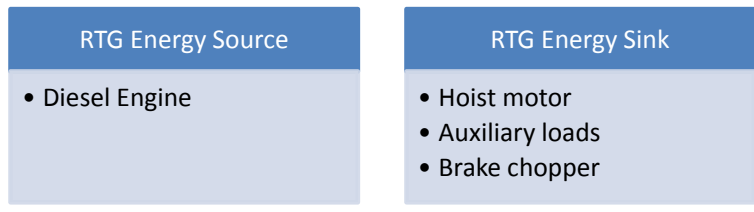

RTG Energy Storage

- Flywheel battery

Auxiliary loads

- Brake chopper

Figure 21. Energy supply/demand components of RTG.
Energy Sink of model

- Resistive load bank 480VDC
Resistive load bank

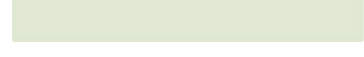

Energy Storage of model

- Vycon Flywheel Battery

Figure 22. Energy source, sink and storage in laboratory. 


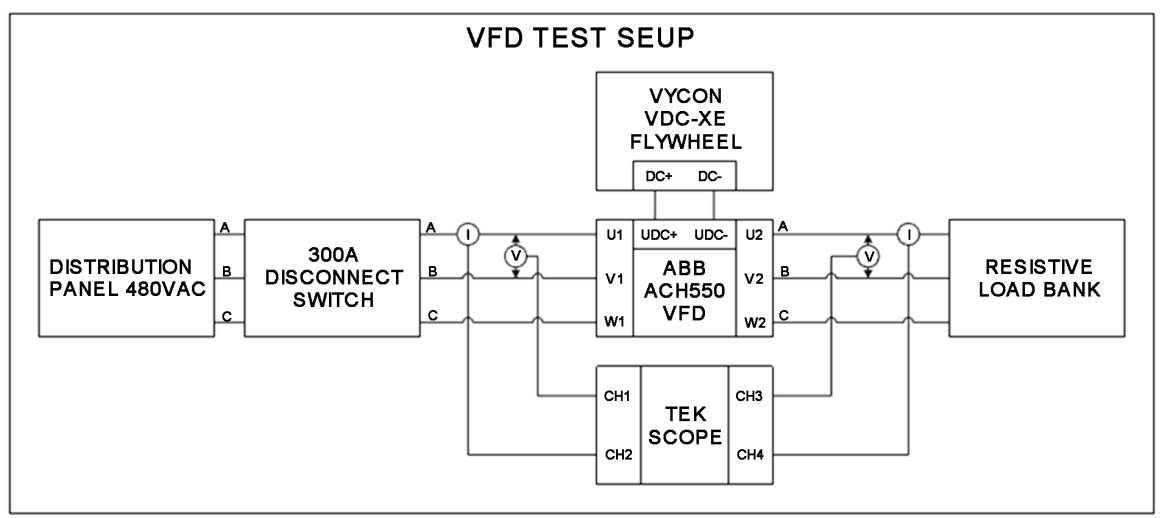

Figure 23. Replicating RTG energy flow in Vycon lab.

they have collaborated with sea ports and universities in conducting their research and tests, including Yantian International Container Terminal, Hutchison Port Holdings, University of Texas at Austin, Ports of Los Angeles and Long Beach, California.

In a lab-based experiment, results show that Vycon (model: VDC-XE) FESS can provide power to a variable speed drive during a loss of utility power. Therefore a similar setup was adopted for building the hardware systems for this project. The setup of Vycon system in their research centre and the results generated are briefly described in the following paragraphs.

In Figure 23, the schematic diagrams show that the distribution power was supplied to an ABB ACH550 VFD via a 300 A disconnect switch. A resistive load bank was applied to the output and the drive was ramped up to $460 \mathrm{~V} / 45 \mathrm{~Hz}$. A VYCON VDC-XE flywheel was connected to the DC terminals of the drive and spun up to full speed. A Tektronix was used to monitor the input and output voltage and current.

Figure 24 is a plot of the flywheel parameters recorded during laboratory test run. When the source from the $480 \mathrm{~V}$ distribution panel is switched off, the DC voltage dips slightly to $600 \mathrm{~V}$ before the flywheel establishes regulation at $625 \mathrm{~V}$. The flywheel continues to supply power to maintain the DC bus at $625 \mathrm{~V}$. While doing so, the rotating speed of the flywheel decreases. When the source returns, the voltage peaks up to $650 \mathrm{~V}$ and the flywheel ramps down power supply and begin to recharge.

The modelling of the hybridized RTG in NTU laboratory is an analogy of the above setup. During RTG hoist up phase, the Variable Frequency Drive will activate a fully charged flywheel to supply power to the resistor bank to maintain the DC bus at a desired voltage. While the RTG is at hoist down regime, the energy from the distribution panel will be the regenerated energy that is supplied to charge the flywheel.

\section{Setup of RTG Models with Flywheel Hardware-in-Loop System in Laboratory}

Hardware that were procured for modelling the RTG system and were delivered to NTU laboratory, include the Variable Frequency Drive (Figure 30), resistors 


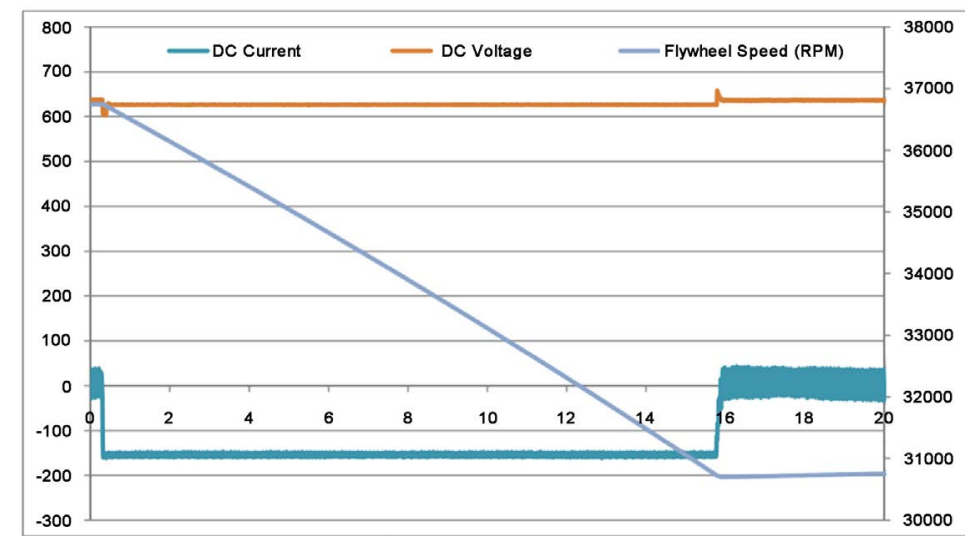

Figure 24. Vycon flywheel performance during lab test.

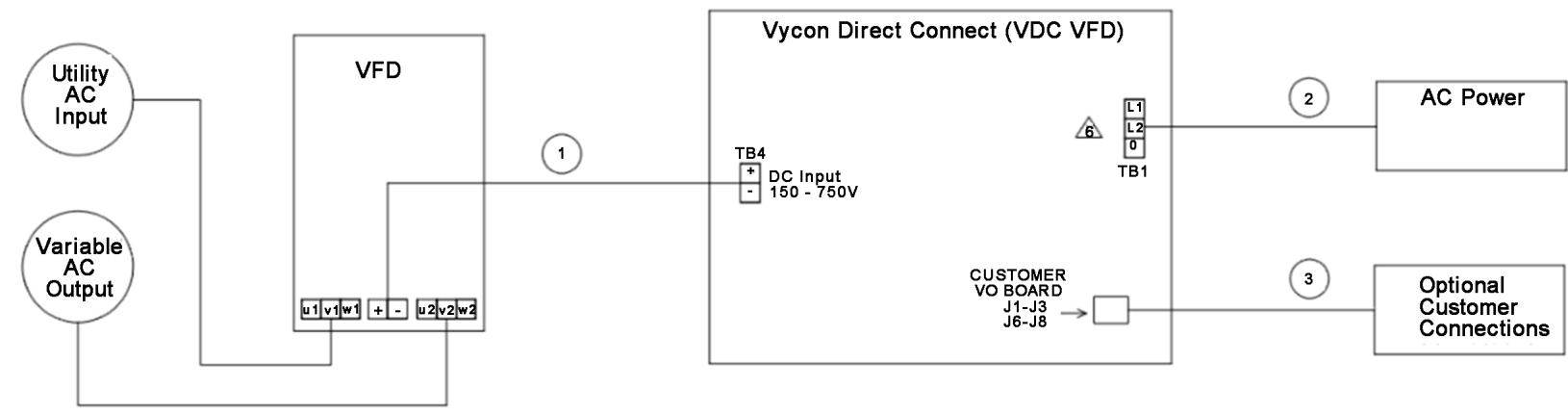

\begin{tabular}{|c|c|c|c|c|c|c|c|}
\hline \multicolumn{8}{|c|}{ INTERCONNECT WIRING } \\
\hline ROUTE & FROM & то & DESCRIPTION & VOLTAGE & CURRENT & TERMINAL & COMMENTS \\
\hline 1 & VFD DC + TERMINAL & TB4/+ & MAIN DC POWER + & 750 VDC MAX & 250A@650VDC & (1) \#6 AWG - 350kcmil Cu or Al & \multirow{3}{*}{ DC CONNECTION TO VFD } \\
\hline 1 & VFD DC - TERMINAL & TB4/- & MAIN DC POWER - & 750 VDC MAX & $250 \mathrm{~A} @ 650 \mathrm{VDC}$ & (1) \#6 AWG - $350 \mathrm{kcmil} \mathrm{Cu}$ or $\mathrm{Al}$ & \\
\hline 1 & VFD POWER GROUND & GROUND BUS & POWER GROUND & GROUND & & (1) \#6 AWG - $250 \mathrm{kcmil} \mathrm{Cu}$ or $\mathrm{Al}$ & \\
\hline & & & & & & & \multirow{4}{*}{ AC POWER FROM UTILITY } \\
\hline 2 & AC UNE & TB1-L1 & AUXILIARY POWER LINE & 600 VAC MAX & NOTE 6 & (1) \#22 - \#10 AWG & \\
\hline 2 & AC UNE & TB1-L2 & AUXILIARY POWER LINE & 600 VAC MAX & NOTE 6 & (1) \#22-\#10 AWG & \\
\hline 2 & AC GROUND & TB1-G & AUXILIARY POWER GROUND & GROUND & NOTE 6 & (1) \#22 - \#10 AWG & \\
\hline
\end{tabular}

Figure 25. Schematic diagram of complete hardware package connections used for modelling RTG hybridized with FESS.

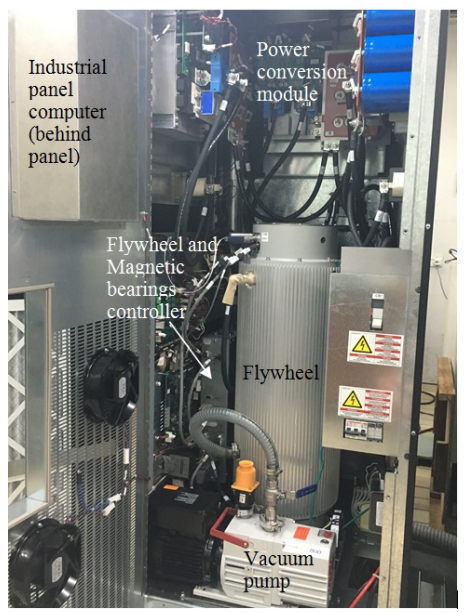

Figure 26. Vycon FESS installed in Nanyang Technological University, school of mechanical and aerospace engineering, mechanics of machines laboratory. 


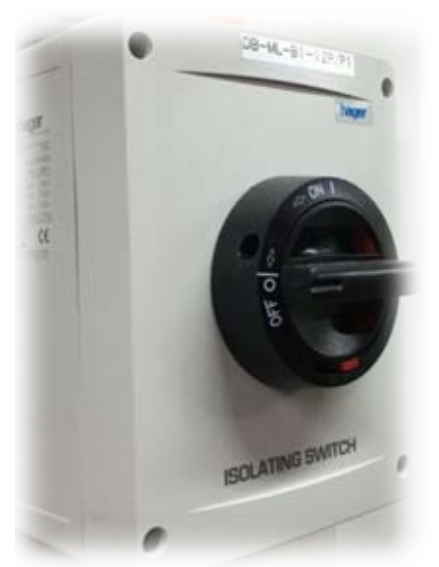

Figure 27. Utility AC input (3-phase power supply from laboratory distribution panel).

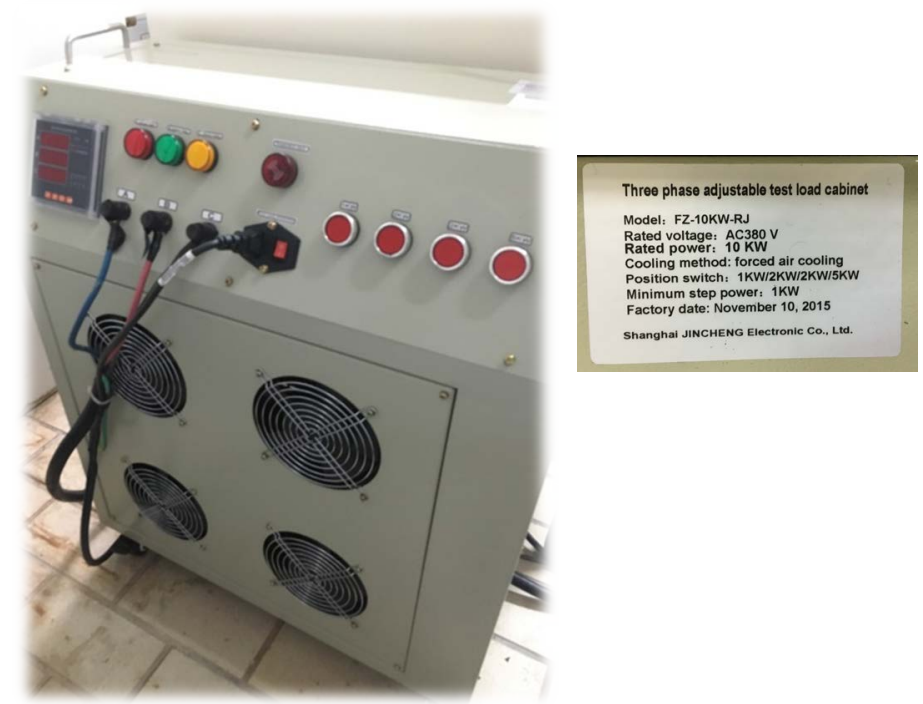

Figure 28. Variable AC output (resistors bank).

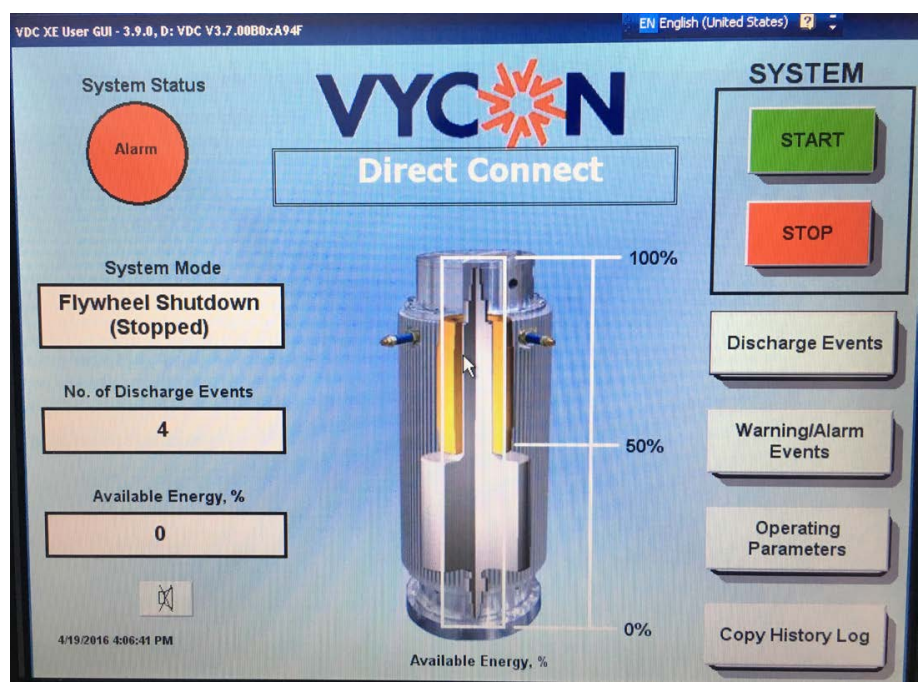

Figure 29. Vycon direct connect FESS touch screen control panel. 


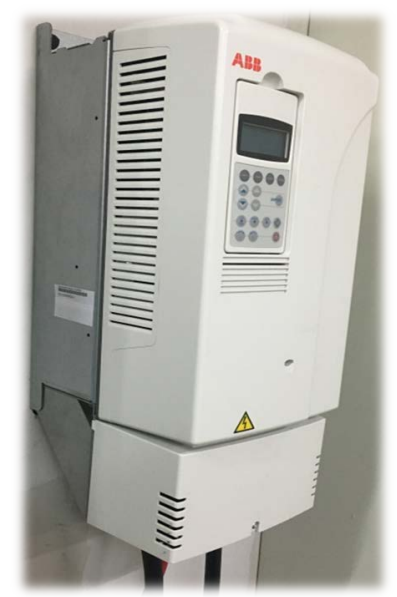

Figure 30. VFD—Variable Frequency Drive.

\begin{tabular}{|c|c|c|}
\hline Description & Value & Remark \\
\hline Moves per hour & 13.3 moves & \\
\hline Hours of operation a day & 16hours & \\
\hline Days of operation a year & 313 days & \\
\hline Moves a year & 66,606 moves & \\
\hline Fuel consumption of generator & 2.23litre/move & \\
\hline Fuel consumption per year & 148,532 litres & \\
\hline Fuel cost per year & $118,825 S G D$ & Diesel @ SGD\$0.8per litre \\
\hline $\begin{array}{l}\text { Average hoisting energy required per } \\
\text { move }\end{array}$ & $7.8 \mathrm{MJ}$ & From simulation results \\
\hline Hoisting energy required per year & $519,526 \mathrm{MJ}$ & \multirow{3}{*}{$\begin{array}{l}36.7 \% \text { of the hoist energy } \\
\text { (From simulation results) }\end{array}$} \\
\hline Flywheel savings & $190,666 \mathrm{MJ}$ & \\
\hline Flywheel savings in kWh & $52,962 \mathrm{kWh}$ & \\
\hline Fuel consumption of generator & 0.535 litre/kWh & $\begin{array}{c}\text { 2.23litre/move } \\
4.17 \mathrm{kWh} / \text { move (Simulation) }\end{array}$ \\
\hline $\begin{array}{l}\text { Reduced fuel consumption per year } \\
\text { per RTG }\end{array}$ & 28,322 litres & \\
\hline Cost saving per year per RTG & $22,658 \mathrm{SGD}$ & Diesel @ SGD\$0.8per litre \\
\hline
\end{tabular}

Figure 31. Monetary saving using RTG crane hybridized with FESS.

bank (Figure 28) and FESS (Figure 26 and Figure 29). The complete system of components were installed and commissioned according to Figure 25 schematic diagram (Figure 27).

A functioning flywheel energy storage system with components required for modelling a RTG has been established in NTU laboratory. This hardware-inloop system can now be integrated to the mathematical models created in the Matlab environment.

\section{Conclusions}

Figure 31 presented the economic advantage of using FESS on RTG crane based on the number of moves per year. (A "move" is defined as relocating a single 20foot container from one place to another). In addition, flywheel system has shown through simulation to greatly reduce energy and fuel consumption. Nevertheless, reducing peak power demand from the diesel engine will prolong engine life. Furthermore, due to the energy storage made available by the flywheels, 
the Variable Speed Generator or conventional Diesel Generator can be reduced in size for greater fuel and carbon emission saving.

The simulation results presented in this paper are generated by using mathematical models of the RTG crane and FESS. The hardware-in-loop simulations will be done in the next project phase and presented in subsequent publications. Nevertheless, the final hardware-in-loop system can be used to simulate power management and energy saving in smart power grid, ships, forklift trucks, prime movers and trains, via the integration of FESS.

\section{Acknowledgements}

We wish to acknowledge the funding support for this project from The Maritime and Port Authority (MPA) of Singapore and Nanyang Technological University (NTU), through the Maritime Clean Energy Research Programme (MCERP). We greatly appreciate the technical support and technical data of Vycon FESS provided by James Yang and Paul Tung from Beijing Balfour (Vycon Distributor in China). We would also like to thank PSA Singapore for providing us the technical data of their Rubber Tyred Gantry Crane.

\section{References}

[1] Alan, R. (2003) Investigation on Storage Technologies for Intermittent Renewable Energies: Evaluation and Recommended R\&D Strategy (INVESTIRE NETWORK).

[2] Knight, C., Becerra, V., Mayer, R. and Holderbaum, W. (2012) Energy Storage on RTG Cranes. https://www.reading.ac.uk/web/files/tsbe/Knight_Poster_2012.pdf

[3] Kim, S.M. and Sul, S.K. (2006) Control of Rubber Tyred Gantry Crane with Energy Storage Based on Supercapacitor Bank. IEEE Transactions on Power Electronics, 21, 1-2. https://doi.org/10.1109/tpel.2006.880260

[4] Siemens, A.G. (2008) Saving Fuel Using ECO-RTG Hybrid Drive System. Proceedings of the TOC Asia Conference 2008, Shanghai, 18 March 2008, 11.

[5] Ichihara, T., Matsunaga, K., Kita, M., Hirabayashi, I., Isono, M., Hirose, M., Yoshii, K., Kurihara, K., Saito, O., Saito, S., Murakami, M., Takabayashi, H., Natsumeda, M. and Koshizuka, N. (2004) Application of Superconducting Magnetic Bearings to 10 kWh Class Flywheel Energy Storage System. https://www.researchgate.net/publication/224614673_Application_of_Superconduc ting_Magnetic_Bearings_to_a_10_kWh-Class_Flywheel_Energy_Storage_System

[6] Schweitzer, G. Active Magnetic Bearings-Chances and Limitations. (2002) Proceedings of the 6 th International IFToMM Conference on Rotor Dynamics, Sydney, 30 September-3 October 2002, 1-11.

[7] Liebherr (2012) Technical Description Liebherr Rubber Tyre Gantry Crane (RTG). https://www.liebherr.com/shared/media/maritime-cranes/downloads-and-brochure s/brochures/lcc/liebherr-rtg-cranes-technical-description.pdf

[8] Zhang, F., Longoria, R.G., Thelen, R. and Wardell D. (2002) A Simulation-Based Design Study for a Locomotive Electric Power System. https://repositories.lib.utexas.edu/bitstream/handle/2152/30648/PR_332.pdf?sequen $\underline{\mathrm{ce}=1}$ 
Submit or recommend next manuscript to SCIRP and we will provide best service for you:

Accepting pre-submission inquiries through Email, Facebook, LinkedIn, Twitter, etc. A wide selection of journals (inclusive of 9 subjects, more than 200 journals)

Providing 24-hour high-quality service

User-friendly online submission system

Fair and swift peer-review system

Efficient typesetting and proofreading procedure

Display of the result of downloads and visits, as well as the number of cited articles Maximum dissemination of your research work

Submit your manuscript at: http://papersubmission.scirp.org/

Or contact jpee@scirp.org 